Article

\title{
The Flipped Classroom as a Pedagogical Tool for Leadership Development in Postgraduate Medical Education
}

\author{
Alicia T. Lucardie ${ }^{1}$ and Jamiu O. Busari ${ }^{2,3, *}$ \\ 1 Faculty of Health, Medicine and Life sciences, Maastricht University, Universiteitsingel 60, \\ 6229 ER Maastricht, The Netherlands; alicialucardie@gmail.com \\ 2 Department of Educational Development and research, Faculty of Health, Medicine and Life sciences, \\ Maastricht University, Universiteitsingel 60, 6229ER Maastricht, The Netherlands \\ 3 Department of Pediatrics, Zuyderland Medical Center, Henri Dunantstraat 5, 6419 PC Heerlen, \\ The Netherlands \\ * Correspondence: Jamiu.busari@maastrichtuniveristy.nl or j.busari@zuyderland.nl; Tel.: +31-455-767-516
}

Received: 8 May 2017; Accepted: 7 June 2017; Published: 13 June 2017

\begin{abstract}
Following a needs assessment among residents, a 10-module leadership curriculum was developed that included health care law and medical errors. An educational intervention using the flipped classroom model (FCM) was developed and we investigated (1) its effectiveness as a teaching method, and (2) the degree of knowledge acquisition of the content of the module. Thirty-four residents were selected using convenience sampling and were divided into an intervention group $(n=10)$ and a control group $(n=24)$. The residents in the intervention group received reading materials and assignments in preparation for two reflective sessions. The control group only received reading material. Multiple-choice questionnaires were used to measure knowledge acquisition. Qualitative interviews were used to assess the perceived effectiveness of the FCM. Eight residents from the intervention group and 10 from the control group were used for final analysis. A significant improvement was observed in acquired knowledge of health care law and medical errors in the intervention group and the FCM was perceived to be effective in teaching health care law and medical errors. The FCM was perceived to facilitate residents' knowledge acquisition and stimulate active learning. Interventions with FCM positively influence residents' performance and should play more structural roles in postgraduate medical education.
\end{abstract}

Keywords: flipped classroom; medical education; leadership; postgraduate; Millennials; residents; health care law; medical errors

\section{Introduction}

In the last decade, an unprecedented change in the need for and delivery of health care has pushed the field of medicine into new and undiscovered territory [1-3]. There has been an increase in the consumption of health care services, and the scope and content of the responsibility of physicians as health care providers have shifted [2,4]. The traditional patriarchal physician-patient relationship has also witnessed a transition into the biopsychosocial model of health care delivery, opening the doors for shared decision-making in the management of health care problems [5,6]. This shared decision-making process, however, progresses beyond the interactions at the individual patient-physician level to involve more patient participation. As a result, there is a demand for improved and more complex standards of health care service in addition to the reorganization and redistribution of health care providers' duties and responsibilities $[2,7,8]$. Consequently, physicians are expected to excel in both their clinical duties as well as in the management of health care processes, often taking up managerial and leadership positions without any formal education [3]. 
Aware of these changing demands, several (postgraduate) medical institutions and national licensing bodies responded differently in the way they reformed their national training programs [1,2,9-11]. For example, the Accreditation Council for Graduate Medical Education (ACGME) in the USA, formulated six competencies that residents needed to acquire during their residency training [1,12] while the Royal College of Physicians and Surgeons of Canada developed the CanMEDS framework consisting of seven professional competencies [1,2,13]. However, since the inception of the CanMEDS framework, many countries including the Netherlands have embraced this framework in the development of curricula for their undergraduate and postgraduate medical programs [2]. In 2015, the CanMEDS framework underwent its latest revision in which one of the professional competencies, i.e., 'Manager' was recoined 'Leader' to better reflect the spectrum of leadership skills and capabilities physicians needed to develop [14-16].

In 2014, a new leadership curriculum for postgraduate medical training programs was developed in our institution at the Faculty of Health, Medicine and Life Sciences at Maastricht University, in the Netherlands. This curriculum was a product of an extensive needs assessment survey conducted among Dutch medical residents and faculty [17-19]. The curriculum comprised of ten topics, ranging from knowledge of the health care system to health care law and medical errors [17]. However, one of the highly-ranked topics from the needs assessment in which residents needed additional training in was 'medical errors and legal aspects of health care' [19]. It is a given that physicians are confronted with a myriad of legal issues on an almost daily basis. In many of these cases, a lack of knowledge of the applicable laws and regulations exists and in situations where they are present; they are not implemented effectively. It is argued in the literature, that a knowledge gap exists between the concept of the legal aspects of health care and its implementation in postgraduate medical training programs [20]. Furthermore, the attention given to this topic in various undergraduate and graduate medical programs is neither structured nor sufficient to prepare medical trainees well for their future leadership roles.

Therefore, to address this educational need, we decided to develop a training module on health care law and medical errors, which was one of the ten themes identified from the needs assessment survey [17]. In the process, we set out to investigate (1) if the educational intervention would improve the trainees' knowledge of the legal aspects of health care and medical errors, and (2) if our chosen educational approach (i.e., the flipped classroom) is an effective pedagogical model to teach Millennial residents. By Millennial residents, we meant the current generation of tech-savvy medical trainees (1985-2005 and later) whose worldview is crafted through the lens of digital technology and social media $[5,6]$.

The flipped classroom method is a pedagogical approach that essentially reverses or 'flips' around the core elements of traditional teaching, i.e., the homework and class sessions [21,22]. Within the traditional model, students prepare for class sessions by reading textbooks and other educational materials beforehand. They then participate in predominantly teacher-centerd classroom interactions and their role in the learning process is relegated to a passive activity [21,23]. The flipped classroom model (FCM) on the other hand actively stimulates students to prepare and engage in the in-class delivery of their learning tasks [24]. Our rationale for choosing the FCM was therefore based on the potential benefits of the educational approach and its intrinsic ability to stimulate interaction and collaboration among learners. Our hypothesis was that the knowledge gained by trainees in a FCM group (using an active learning process) would be higher than that of trainees in a control group that uses a passive learning approach. Our second hypothesis was that the FCM is an effective educational modality to teach health care law and medical errors to Millennial residents. 


\section{Materials and Methods}

\subsection{Study Design}

\subsubsection{Setting and Participants}

Residents from clinical-related specialties at Zuyderland hospital in the South of the Netherlands were approached to fill in an online knowledge questionnaire on health care law and medical errors and to participate in a training module on these topics through convenience sampling (email invitation). Convenience sampling is a non-probability sampling method where participants are selected from a convenient, accessible population. Residents who did not apply to participate in the training module were allocated to serve as the control group (see Procedures section below). All residents from Zuyderland hospital from all years of residency were eligible for inclusion, provided their term of residency did not expire before the end of data collection (at the time of participant selection). There were no explicit exclusion criteria. Ethical approval from Zuyderland Medical Ethics Committee (METC) was sought before the start of the intervention and approved.

\subsubsection{Instructor Selection}

Based on the findings of earlier research [1,25], one content and one field expert were recruited to facilitate the training module. Each expert was responsible for one session, i.e., either health care law or medical errors.

\subsubsection{Instructional Tools}

In designing this module, we chose to use the FCM as our method of instruction because: (a) It resonates well with the differing expectations and educational needs of different generation of learners [5,6], and (b) It can facilitate the quick transition from merely understanding a theoretical subject to higher order cognitive skills in students [26,27]. A recent systematic review on the FCM approach (Chen et al. 2017) also justified the FCM as a promising teaching approach, when the intent is to increase the motivation, task value and engagement of learners. The review showed that the competencies gained from the FCM was at least as effective as traditional education. In addition, students liked the FC methodology of education although, regardless of curricular approach, high student expectations and social pressure were confounding influences on students' learning experiences. Other potential limitations included the effect of temporal factors on the outcome of learning, such as time spent in and outside of class, in clinical work, and on personal activities [28].

\subsubsection{Content and Format of the Training Module}

Careful attention was paid to both the content and format of the training module prior to implementation, ensuring a thorough understanding of the intended learning outcomes (ILOs), preparation materials and exercises, in-class content and the FCM as a viable teaching method [29-31]. The training module on health care law and medical errors that we designed was based on the method described by Lockyer et al. (2005) [22,29]. Following an extensive needs assessment [17-19], we proceeded to develop the ILOs for both topics. Using Bloom's Taxonomy (revised edition) [30,32], we divided the ILOs into both lower- and higher-order learning activities. The ILOs were designed to provide both teachers and residents with a structured guideline on the aims and expectations of the module (see Intended Learning Outcomes (ILOs), Tables 1 and 2). Class time was divided into two sessions of two hours each on the topics of health care law and medical errors. Higher-order active learning strategies such as application and evaluation of knowledge were encouraged through case-based discussion, debate and role-play [22,29,30].

Intended Learning Outcomes (ILOs) of the training module: 
Table 1. Cognitions.

\begin{tabular}{ll}
\hline Training Health Care Law & Training Medical Errors/Negligence \\
\hline $\begin{array}{l}\text { remembering, understanding } \\
\text { - Knowledge of the different types of law }\end{array}$ & - $\begin{array}{l}\text { The implications of medical incidents and errors } \\
\text { for the patient and medical staff }\end{array}$ \\
- Knowledge of health care laws in the Netherlands & $-\quad \begin{array}{l}\text { The difference between medical incidents, } \\
\text { complications, calamities and errors. }\end{array}$ \\
- Knowledge of a disciplinary claim procedure & \\
\hline
\end{tabular}

Table 2. Cognitive skills.

\begin{tabular}{ll}
\hline Training Health Care Law & Training Medical Errors/Negligence \\
\hline applying, analysing, evaluating, creating & - $\begin{array}{l}\text { (Early) recognition of red flags in the process of } \\
\text { care and identification of possible solutions }\end{array}$ \\
$\begin{array}{l}\text { Evaluate the measures issued by the Medical } \\
\text { Disciplinary Council in case studies }\end{array}$ & $\begin{array}{l}\text { Make sounds decisions/judgements on the } \\
\text { provention of medical errors } \\
\text { adequately apply health care laws to daily practice }\end{array}$ \\
- $\begin{array}{l}\text { Have the capability to inform both patients and law } \\
\text { enforcement adequately }\end{array}$ & $\begin{array}{l}\text { Apply the procedure of reporting a medical } \\
\text { incident in a hospital }\end{array}$ \\
\hline
\end{tabular}

\subsubsection{Questionnaire Design}

An online multiple-choice questionnaire was designed to assess the knowledge gained in health care law and medical errors. The content of the questionnaire focused on the topics outlined in the ILOs as well as on aspects of the homework and pre-class assignments. The questionnaire was developed by AL and JB together with three content experts in the field of legal aspects of health care and medical errors and an expert in questionnaire design. The initial draft of our pilot questionnaire consisted of 50 items. The reliability and utility of the questionnaire was tested in a pilot study among residents in the departments of Paediatrics and Obstetrics/Gynaecology at the Maastricht University Medical Centre (MUMC+) in the Netherlands. Forty-five residents were approached by email (convenience sampling) for this purpose and 15 of them completed and returned the questionnaires as requested (response rate $33.33 \%$ ). The test of reliability of the 50 multiple choice questions in the original questionnaire initially revealed a Cronbach's alpha of 0.264 . This subsequently increased to 0.709 following an iterative stepwise removal of the items to 30 .

Feedback (quantitative and qualitative) on the questionnaire's suitability for testing resident's knowledge of the topics were obtained from the residents in a separate section of the questionnaire. On a scale of $1-5(1=$ very poor; $5=$ excellent $)$ the content of the questionnaire was scored with an average of 3.69 (range 3-5). The format of the questionnaire was graded with an average of 4.00 (range 3-5). Seven residents found the length of the questionnaire "exactly right", 6 "a bit too long", and two found it "much too long". Open ended questions were also used to solicit their opinions on how the questionnaire could be improved. Only Six residents responded. One suggested that the questions should be shortened and another one felt the number of question too much citing that "there were too many questions, which means you cannot read the content properly and therefore have to scan the question; this influences your outcome". A third resident suggested that supplementary literature to assist in preparation could be helpful. The other three residents did not give direct feedback on the questionnaire. All fifteen of the residents indicated they wanted to follow a training on the topics. The final 30-item questionnaire was uploaded into SurveyMonkey, a web-based questionnaire and survey tool (www.surveymonkey.com). 


\subsection{Data Collection}

\subsubsection{Knowledge Acquisition}

This is the process of bundling and packaging (new) ideas or concepts in a way that learners can easily retrieve and apply them to solve problems later [33,34]. To assess the degree to which the learners acquired and retained the content of our module, a 30-item questionnaire was developed to test the participants' knowledge before and after the module. The questionnaire items in both the pre- and post-tests were identical but organized randomly to curb the influence of item memorization. Finally, the respondents were asked to provide an estimation (grades) of the outcome of their performances in the knowledge tests (using a weighted scale of $1=$ very poor and $10=$ excellent). This was to examine any direct influence the intervention may have had on the respondents perceived level of acquired knowledge and if there was any correlation with actual knowledge test performance.

\subsubsection{Perceived Effectiveness of FCM}

In addition to assessment of knowledge acquisition, the perceived effectiveness of the FCM in teaching health care law and medical errors was assessed. This was done to gain insight into both the positive and negative aspects of the training module [35]. A series of face-to-face, audio-recorded semi-structured interviews were conducted with the participants in the intervention group. The semi-structured interview is a well-established qualitative method, that is useful for eliciting answers to "why" questions. The inherent flexibility of the method makes it possible to adjust the structure and scope of questions to explore what participants consider to be important during the interview [36]. The interviews, which lasted a maximum of 30 minutes to minimize constraint on residents, were conducted after the successful completion of the training session. A series of 4-6 questions/topics were designed to guide the interviews (covering strengths and weaknesses for topics central to effectivity such as content, format, and methods of preparation). Written informed consent was given before the start of the interviews. Anonymity and confidentiality were explicitly guaranteed before each interview [35].

\subsection{Procedures}

\subsubsection{General Procedure}

The general procedure for this study was based on an earlier pilot study by Berkenbosch et al. (2014) evaluating a practice management training for residents [35]. The online 30-item multiple choice questionnaire assessed the prior knowledge of all residents on the topics of health care law and medical errors, two weeks before the start of the training module. Upon completion of the knowledge questionnaire, homework materials were assigned to both the intervention and control groups, focusing primarily on lower cognitive activities such as remembering and understanding [22].

\subsubsection{Intervention Group}

In addition to the baseline homework materials, the intervention group received specific preparatory exercises that included a selection of resources from standard textbooks and research articles that were accessible online. They were also instructed to view preselected (open access) videos online about health care law and medical errors. Specific assignments were given to them to complete based on the video's they watched and the reading materials they studied.

Following the guided individual activities that the residents were given, they were invited to attend an interactive leadership training module on health care law and medical errors. This module comprised of two separate two-hour sessions of group discussions in which the residents reflected, recreated and reorganized their understanding of the concepts acquired from their individual learning activities. The content experts facilitated these sessions and helped where needed to clarify difficult or confusing concepts. At the end of the module, an evaluation of the sessions was performed to identify 
how the residents perceived the program and determine the areas that required improvement i.e., learning climate, level of interaction, educational content, quality of instruction/trainers and overall impression of the module, to help improve it. Two weeks after the interactive session, the residents in both groups received the same 30-item multiple choice questionnaire again, with the order of the items randomized. The intervention group was also asked to participate in individual semi-structured interviews, to further investigate their perceived effectiveness of the FCM of training.

\subsection{Data Analysis}

Analyses were performed using IBM SPSS Statistics version 23. Descriptive analyses of baseline characteristics for all participants were conducted. Non-parametric tests were used to analyze participants' knowledge acquisition. Significance was defined as a p-value greater than 0.10 .

Qualitative data from the semi-structured interviews were transcribed verbatim and thematic analysis was used to inductively analyze the data. Transcripts were reviewed by AL and excerpts revealing participants' perceptions of the FCM were identified and coded using theoretical coding methods (i.e., open coding, axial coding and selective coding) [37]. Codes were grouped into relevant themes and further defined and named (i.e., 1. appreciation of content; 2. valued features; 3. preparatory materials and 4 difference with Problem Based Learning) in collaboration with JB.

\section{Results}

\subsection{Baseline Characteristics}

Ten residents (five from Internal Medicine, two from Paediatrics, and one each from Gastroenterology and Psychiatry) participated in the training module on health care law and medical error (intervention group). The control group consisted of 24 residents (five from Neurology, three each from Surgery and Gynaecology/Obstetrics, two each from Cardiology, Paediatrics and Psychiatry, with Emergency Medicine, Orthopedic Surgery, Plastic Surgery and Radiology each counting one resident). In the intervention group, two residents did not complete the baseline knowledge questionnaire in time and were thus excluded from analyses regarding knowledge acquisition. They did complete the questions regarding baseline characteristics. Of the 24 residents in the control group, fourteen were lost to follow-up and did not complete the post-test. Reasons for not completing the post-test were not given (See Flowchart, Figure 1).

The average age in the intervention group was 29.0 years (range 26-35 years), comparable to the control group with 28.64 years (range 25-35 years). There were more males in the control group compared to the intervention group $(41.7 \%$ vs. $30.0 \%)$. For both groups, all residents had had their basic medical education in the Netherlands, bar one for each group (educated in Belgium). One resident in the control group had had a disciplinary claim and hearing. See Table 3 for descriptive statistics.

Table 3. Baseline characteristics of the residents.

\begin{tabular}{ccc}
\hline & Intervention Group $(\boldsymbol{n = 1 0 )}$ & Control Group $(\boldsymbol{n}=\mathbf{2 4})$ \\
\hline Average age (years) & $29.00(26-35)$ & $28.64(25-35)$ \\
Gender (male) & $3(30.0 \%)$ & $10(41.7 \%)$ \\
Years of experience & & \\
$<1$ & $1(10.0 \%)$ & $7(29.2 \%)$ \\
$1-2$ & $3(30.0 \%)$ & $7(29.2 \%)$ \\
$3-4$ & $3(30.0 \%)$ & $7(29.2 \%)$ \\
$5-6$ & $2(20.0 \%)$ & $3(12.5 \%)$ \\
$>6$ & $1(10.0 \%)$ & $0(0 \%)$ \\
Basic Medical education & & \\
Netherlands & $9(90.0 \%)$ & $23(95.8 \%)$ \\
Belgium & $1(10.0 \%)$ & $1(4.2 \%)$ \\
\hline
\end{tabular}




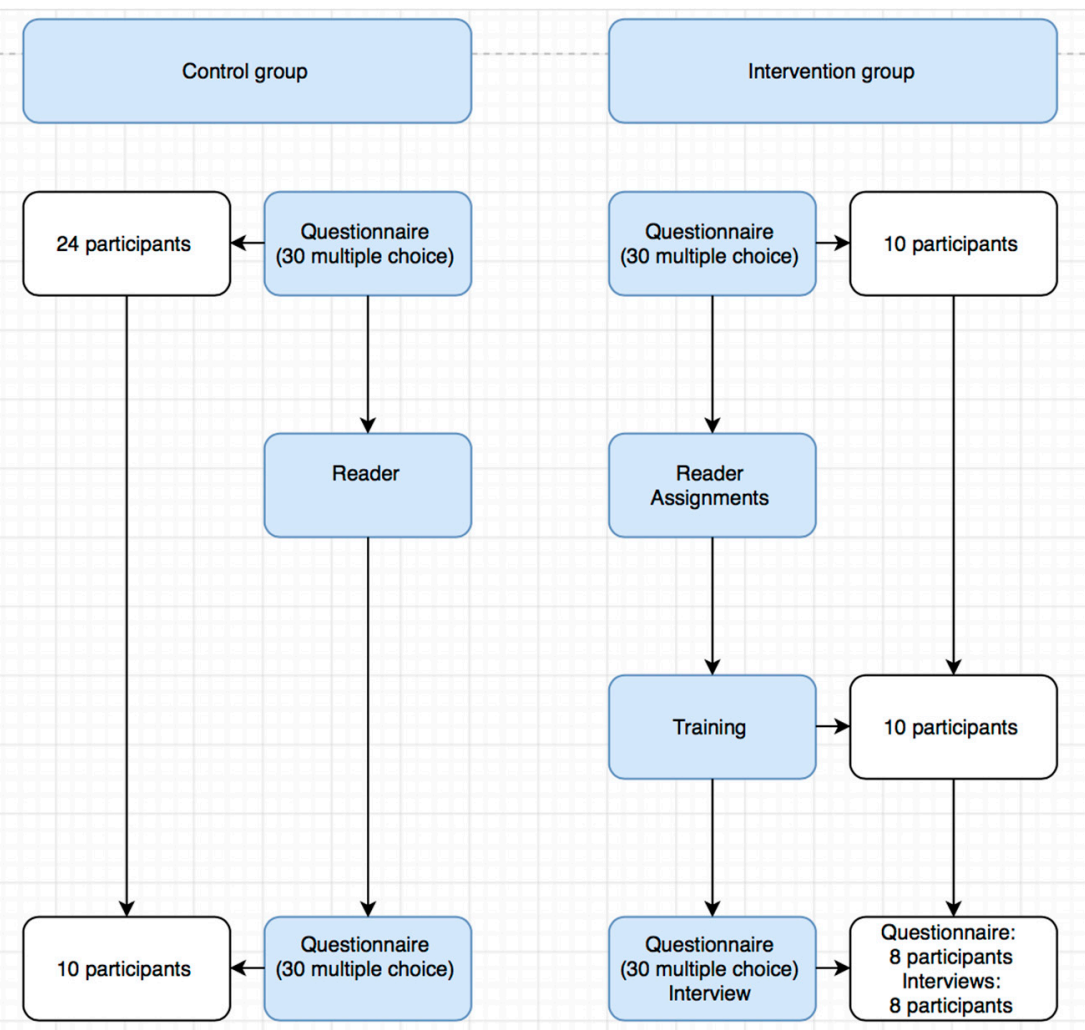

Figure 1. Flowchart of the process of resident selection.

\subsection{Knowledge Acquisition}

From the group of residents who had completed both the pre- and post-test knowledge questionnaire, the residents in the intervention group $(n=8)$ scored on average $57.14 \%$ (95\% CI 48.53-65.76) for the pre-test. The residents in the control group $(n=10)$ scored on average $62.78 \%$ (95\% CI 59.91-65.64) for the pre-test. In the intervention group, the average post-test score was $66.67 \%$ (95\% CI 60.72-72.61) compared to the control group 63.67\% (95\% CI 58.98-68.36).

The data did not meet the assumptions for normality and homogeneity of variance. Thus, we used the non-parametric Mann-Whitney $U$ test to calculate the average difference between pre- and post-test scores for the intervention group (mean rank 12.43) vs. the control group (mean rank 6.60). The average difference in scores for the intervention group differed significantly compared to the control group (i.e., favoring the intervention group), $\mathrm{U}=111.00, \mathrm{z}=1.302, p=0.019, \mathrm{r}=0.31$.

At the end of the post-test, residents were asked to estimate their final grade on a scale of $0-10$. Interestingly, the average score, shown as a percentage, for the residents in the intervention group was $66.00 \%$ (SD 1.26), and the residents in the control group averaged $60.91 \%$ (SD 1.30).

The Wilcoxon signed-rank test showed that for the intervention group, the post-test scores $(\mathrm{Mdn}=70.00)$ were not significantly higher than the self-estimated post-test scores $(\mathrm{Mdn}=70.00)$, $\mathrm{T}=15.5, \mathrm{p}=0.403, \mathrm{r}=0.26$. For the control group, the post-test scores $(\mathrm{Mdn}=65.00)$ also did not significantly differ from the self-estimated post-test scores $(\mathrm{Mdn}=60.00), \mathrm{T}=15.5, p=0.403, \mathrm{r}=0.26$.

\subsection{Semi-structured Interviews}

Of the ten residents that participated in the training, eight took part in the interviews that followed. The purpose of the interviews was to assess the perceived effectiveness of the FCM as well as the quality of the interactive face to face sessions. Two residents were lost to follow-up. One resident cited lack of time; the other left Zuyderland hospital to work at another hospital shortly after the training. 
All eight residents highly appreciated the chosen topic for the training. Resident 1 and 3 commented that as a doctor, health care law and medical errors is something you will "probably come in contact with", and therefore "it is important that you know what you have to do" (resident 4 and 5). The fact that two topics were chosen for the module was experienced as beneficial for inclusion purposes, essentially because one topic may interest a resident more than another (e.g., health care law is "just really boring to read (about)" (resident 2)). Nonetheless, all of them considered knowledge of both topics to be important in postgraduate medical education.

The most valued feature of the FCM was the high degree of interaction that the residents experienced during the two sessions. One of the respondents said that it created an "open atmosphere (enabling us) to talk freely and the facilitator was "instrumental" in the process" (resident 6). They highly appreciated the direct comparison of theoretical concepts to real life practice situations during the face to face interactions. There was also some discussion about the total duration of the training. Three residents would have preferred a longer length of time for the training module. One resident said that "practically one day is easier ... but...effectively speaking two afternoons (would be better); it may lead to better retention of the material" (resident 2). Two other residents supported this suggestion. Residents valued the small group size (resident 3 and 6) and the fact that the facilitators were either a content specialist and/or clinician.

Regarding the preparation materials, the residents appreciated receiving content materials ahead of class time (resident 2, 3 and 6). It is "useful to prepare in advance and then build on the topic during class" (resident 2). However, some of them felt that the amount of preparatory reading materials was too much (resident 1 and 8 ) and would have preferred a few key articles. Both residents admitted having no prior experience with this method of preparation (i.e., selective learning). Six residents would have preferred a longer preparation time, though the time deemed necessary varied from a few days to two weeks. One resident said that he was now used to receiving information "kind of ready-made", so actively looking up information took some getting used to, even though this should be standard practice" (resident 8). The questionnaire served as a useful tool to trigger the learning process (resident 5 and 7). Two residents preferred reading materials over video, because of practical reasons in the workplace, for example, blocked websites (resident 1 and 5).

Most residents understood how the FCM differed from Problem Based Learning (PBL), which was regularly used at Maastricht University in the Netherlands (resident 1, 2, 5, 6, 8). Interestingly, one resident (6) mentioned that one of the greatest benefits of the FCM compared to PBL was that, "you are informed ahead of time, about the important things to pay attention to, the relevant definitions ... etc. With problem based learning I noticed time and again that everyone had picked up on something else ... so sometimes you completely focused on the wrong things, leaving aside the truly relevant things".

Overall, the residents were very satisfied with both the content and format of the training, bar minor adjustments to the preparation materials and duration of the preparation. In fact, one resident commented that the training module should become a "compulsory element within postgraduate medical education".

\section{Discussion}

In this study, a training module on health care law and medical errors for Millennial residents was designed using the FCM. We then set out to investigate if this educational intervention resulted in significant knowledge acquisition of these topics and test if the FCM was an effective teaching method for this purpose i.e., teaching health care law and medical errors. The results of this study indicate that the FCM was perceived to be both effective in increasing residents' knowledge of the topic as well as an effective educational tool. Knowledge acquisition was significantly higher in the FCM group, compared to the control group. In addition, the residents valued the training module highly. Central to this were the notable levels of interaction during the training and the direct application of content to the practice setting. The qualitative data also suggest that the FCM is effective in teaching Millennial residents' health care law and medical errors. 
In general, there are multiple advantages to the FCM. First, the model caters to the educational needs of the individual Millennial student $[22,38]$ through high levels of interaction and collaboration [6]. This was supported by evidence from the semi-structured interviews. Secondly, it allows students select their preferred learning styles and control both time and pace of learning [39] thereby providing them with the opportunity to take 'responsibility for their own education' [22,35]. Thirdly, students receive a list of literature and audio/video materials beforehand from which they can source their information. Guided with triggering, practical questions, students learn the basic concepts ahead of class so that face to face class time can be devoted to 'higher-order learning activities' such as discussions and practical scenarios and thereby optimizing student-teacher and student-student interaction time [22,40]. Also, external experts can be recruited, which would otherwise not have been possible given both time and geographical constraints [22]. Lastly, and most importantly, the model allows for the direct application of newly acquired knowledge to the practical setting, especially in the case of largely theoretical topics such as health care law and medical errors. This is crucial in today's fast-paced, highly complex health care system, where residents must continuously adapt to changing situations.

There are also a few disadvantages to the FCM. First, it is essential that students have high intrinsic motivation to guard their own educational process [22]. Second, there is a risk of burdening residents with too much reading material [22]. Preparation involves a time investment, which can be challenging in the highly demanding medical setting. The residents in our study echoed this notion, with some preferring less preparation material. Third, it should be noted that the design and development of the training module initially takes a considerable amount of time and effort [22]. However, once trainers are familiarized with the FCM and a clear framework has been developed, it can be easily re-used for subsequent modules. Regarding the preparatory materials and exercises, there are three potential drawbacks. First, there is the risk of using technology for the sake of technology [21]. This concerns both virtual learning environments (VLEs) and the use of video material. Contrary to popular thought, the driving factor behind the success of the FCM is not based on the availability and use of pre-recorded video lectures [21,22]. Rather, the role of technological tools lies in supporting a "sound pedagogical teaching strategy" [22,41].

Despite the interesting findings in this study there were a few challenges that we faced. The first was the selection of the residents which was based on convenience sampling from a convenient and easily accessible population. Inherent to this method is selection bias, leading to problems with respect to generalization. An advantage with this method however, is that it best reflects the practice situation with differing levels of dedication among residents. This could possibly explain the difference in the numbers we lost to follow-up for the intervention group $(20.00 \%)$ compared to the control group $(58.33 \%)$. We assumed that that the less committed residents probably dropped out first [32]. Unfortunately, we do not have data to explain the individual reasons behind the loss to follow-up. While our results showed a significant difference in knowledge acquisition in favour of the intervention group, the small size of our sample constituted a potential limitation. For example, we needed 21 participants in each arm of our study to detect a large effect with a power of $80 \%(a=0.05)$. Unfortunately, we were only able to allocate 10 residents to the intervention group.

Furthermore, the difference in knowledge acquisition between the intervention and control groups could be attributed to the different amount of exposure to the content, and not necessarily the FCM itself. For example, assuming both groups spent the same amount of time on the preparation materials, the intervention group had an extra four hours of exposure to the topic content, simply by attending a training. In fact, the results showed that the intervention group spent an average of $2.63 \mathrm{~h}$ (range $0-4$ ) on the preparation materials, compared to the control group (0.40 h; range $0-1)$.

Even though some residents would have preferred the training to have been longer or spread out across multiple days, residents' perception of the training module was very high, and this was reflected in both the group evaluation and during the interviews. While we acknowledge that this study is preliminary in nature and the results need to be replicated in future studies, we believe that 
the training module could have a lasting impact on residents' performance (specifically for Millennial residents). This is supported by the call for more studies with a focus on how to increase sample size and follow-up time in the systematic review of Chen et al., (2017) as both issues are essential in increasing the reliability and generalization of research findings [28]. Other options would be to include a second control group to evaluate the effect of exposure to the questionnaire alone or exposing the passive learning control group to a lecture instead of the FCM training. Lastly, we would highly recommend selecting medical specialties individually for participation, to further increase inclusion rates and reduce loss to follow-up. With this study, we believe that the first careful steps toward an effective untangling of the myriad of medical-legal issues for a new generation of doctors have been made. We believe the FCM is essential in this process and should play a structural role in postgraduate medical education and leadership.

\section{Conclusions}

In conclusion, our study is probably a first example of the application of FCM to teach health care law and medical errors in postgraduate medical education. Compared to the control group who were exposed to a passive learning process (i.e., study materials only), the amount of knowledge acquired was shown to be significantly higher in the residents who participated in the active learning module (FCM). The residents were also satisfied with both the content and format of the training module. Overall, this study demonstrates that the FCM can contribute to the effective teaching of a module in health care law and medical errors, as part of a comprehensive postgraduate medical leadership program.

Acknowledgments: Written informed consent was given before the start of the semi-structured interviews. Anonymity and confidentiality were explicitly guaranteed before each interview.

Author Contributions: Alicia T. Lucardie designed the study, made substantial contribution to the writing of the article, analysis and interpretation of the data, and revision of the article critically for important intellectual content. Jamiu O. Busari conceived and designed the study, made substantial contribution to the writing of the article, analysis and interpretation of the data, and revision of the article critically for important intellectual content. All authors read and approved the final manuscript.

Conflicts of Interest: The authors declare no conflict of interest.

\section{Abbreviations}

The following abbreviations are used in this manuscript:

ACGME Accreditation Council for Graduate Medical Education

CanMEDS Canadian Medical Education Directives for Specialists

ILOs Intended Learning Outcomes

METC Medical Ethics Committee

VLE Virtual Learning Environment

Ethics Approval and Consent to Participate: Ethical approval from Zuyderland Medical Ethics Committee (METC) was sought prior to the start of the intervention. The METC ruled that ethical approval was not necessary based on the requirements of the Dutch Medical Research (Human Subjects) Act.

\section{References}

1. Busari, J.O.; Berkenbosch, L.; Brouns, J.W. Physicians as managers of health care delivery and the implications for postgraduate medical training: A literature review. Teach. Learn. Med. 2011, 23, 186-196. [CrossRef] [PubMed]

2. Berkenbosch, L. Management and leadership education for medical residents. Evaluating needs and developing an educational intervention. In Enschede; Ipskamp Drukkers BV: Amsterdam, The Netherlands, 2014.

3. Ackerly, D.; Sangvai, D.; Udayakumar, K.; Shah, B.; Kalman, N.; Cho, A.; Schulman, K.A.; Fulkerson, W.J., Jr.; Dzau, V.J. Training the Next Generation of Physician-Executives: An Innovative Residency Pathway in Management and Leadership. Acad. Med. 2011, 86, 575-579. [CrossRef] [PubMed] 
4. MacCarrick, G. Chapter 1: Introduction. In Medical Leadership and Management A Case-based Approach; Springer: London, UK, 2014.

5. Busari, J.; Scheele, F. Generatieverschillen: Relevant voor de Nederlandse specialistenopleiding. Ned. Tijdschr. Geneeskd. 2015, 159, A8900. [PubMed]

6. Busari, J.O. The discourse of generational segmentation and the implications for postgraduate medical education. Perspect. Med. Educ. 2013, 2, 340-348. [CrossRef] [PubMed]

7. Keckley, P.; Eselius, L. Survey of Health Care Consumers: Key Findings, Strategic Implications; Deloitte Center for Health Solutions: Washington, DC, USA, 2009.

8. The Royal Dutch Medical Association. Medical Professionalism 2007. 2007. Available online: https: / / www.nza.nl/1048076/1048181/Reactie_KNMG_bijlage_2.pdf (accessed on 9 June 2017).

9. Halpern, R.; Lee, M.Y.; Boulter, P.R.; Phillips, R.R. A synthesis of nine major reports on physicians' competencies for the emerging practice environment. Acad. Med. 2001, 76, 606-615. [CrossRef] [PubMed]

10. Severs, M.; Crane, S. Challenges in medical education-What the doctor ordered? Postgrad. Med. J. 2000, 76, 599-601. [CrossRef] [PubMed]

11. Frank, J.R.; Danoff, D. The CanMEDS initiative: Implementing an outcomes-based framework of physician competencies. Med. Teach. 2007, 29, 642-647. [CrossRef] [PubMed]

12. Swing, S. Assessing the ACGME general competencies: General considerations and assessment methods. Acad. Emerg. Med. 2002, 9, 1278-1288. [CrossRef] [PubMed]

13. Frank, J. The CanMEDS 2005 Physician Competency Framework. Better standards. Better physicians. Better Care. 2005. Available online: http:/ /www.royalcollege.ca/portal/page/portal/rc/common/documents/ canmeds / resources/publications/framework_full_e.pdf (accessed on 9 June 2017).

14. Frank, J.; Snell, L.; Sherbino, J. CanMEDS 2015 Physician Competency Framework. 2015. Available online: http:/ / canmeds.royalcollege.ca/uploads/en/framework/CanMEDS\%202015\%20Framework_EN_ Reduced.pdf (accessed on 9 June 2017).

15. Dath, D.; Chan, M.; Anderson, G.; Burke, A.; Razack, S.; Lieff, S. Leader. In CanMEDS 2015 Physician Competency Framework; Frank, J., Snell, L., Sherbino, J., Eds.; Royal College of Physicians and Surgeons of Canada: Ottawa, ON, Canada, 2015. Available online: http://canmeds.royalcollege.ca/uploads/en/ framework/CanMEDS\%202015\%20Framework_EN_Reduced.pdf (accessed on 9 June 2017).

16. Dath, D.; Chan, M.; Abbott, C. CanMEDS 2015: From Manager to Leader. 2015. Available online: https://www.google.nl/url?sa=t\&rct=j\&q=\&esrc=s\&source=web\&cd=1\&ved= 0ahUKEwiUms355LDUAhWNIlAKHePNAqsQFggqMAA\&url=http\%3A\%2F\%2Fwww.royalcollege. ca\%2Frcsite\%2Fdocuments\%2Fcbd\%2Fcanmeds-2015-manager-to-leader-e.pdf\&usg=AFQjCNFpP4-keTRDxU7IyOhiCUdEgYpxw\&sig2=gbaZdhiCNZAWHJdejofRRw\&cad=rja (accessed on 9 June 2017).

17. Busari, J. Longitudinal curriculum for leadership development. Unpublished work. 2014.

18. Berkenbosch, L.; Brouns, J.W.M.; Heyligers, I.; Busari, J.O. How Dutch medical residents perceive their competency as manager in the revised postgraduate medical curriculum. Postgrad. Med. J. 2011, 87, 680-687. [CrossRef] [PubMed]

19. Berkenbosch, L.; Bax, M.; Scherpbier, A.; Heyligers, I.; Muijtjens, A.M.M.; Busari, J.O. How Dutch medical specialists perceive the competencies and training needs of medical residents in health care management. Med. Teach. 2013, 35, e1090-e1102. [CrossRef] [PubMed]

20. Nelson, E. Teaching law to students in the health care professions. Health Law Rev. 2003, 11, 8-19.

21. Sharma, N.; Lau, C.S.; Doherty, I.; Harbutt, D. How we flipped the medical classroom. Med. Teach. 2015, 37, 327-330. [CrossRef] [PubMed]

22. Moffett, J. Twelve tips for "flipping" the classroom. Med. Teach. 2015, 37, 331-336. [CrossRef] [PubMed]

23. Mazur, E. Farewell lecture. J. Tokyo. Med. Univ. 2012, 70, 141-167.

24. Van den Berg, E.E.P.; Bracey, A.; Van Driel, A.P.G.; Geijsel, F.E.C.; Manders, S. Modular continuing professional development for emergency physicians-The MNSHA masterclass programme. Eur. J. Emerg. Med. 2015, 23, 208-213. [CrossRef] [PubMed]

25. Brouns, J.W.; Berkenbosch, L.; Ploemen-Suijker, F.D.; Heyligers, I.; Busari, J.O. Medical residents perceptions of the need for management education in the postgraduate curriculum: A preliminary study. Int. J. Med. Educ. 2010, 1, 76-82. [CrossRef] 
26. McLaughlin, J.E.; Roth, M.T.; Glatt, D.M.; Gharkholonarehe, N.; Davidson, C.A.; Griffin, L.M.; Esserman, D.A.; Mumper, R.J. The Flipped Classroom: A course redesign to foster learning and engagement in a health professions school. Acad. Med. 2014, 89, 236-243. [CrossRef] [PubMed]

27. Lucardie, A.T.; Berkenbosch, L.; Van den Berg, J.; Busari, J.O. Flipping the classroom to teach Millennial residents medical leadership: A proof of concept. Adv. Med. Educ. Pract. 2017, 8, 57-61. [CrossRef] [PubMed]

28. Chen, F.; Lui, A.M.; Martinelli, S.M. A systematic review of the effectiveness of flipped classrooms in medical education. Med. Educ. 2017, 51, 585-597. [CrossRef] [PubMed]

29. Lockyer, J.; Ward, R.; Toews, J. Twelve tips for effective short course design. Med. Teach. 2005, 27, $392-395$. [CrossRef] [PubMed]

30. Galway, L.P.; Corbett, K.K.; Takaro, T.K.; Tairyan, K.; Frank, E. A novel integration of online and flipped classroom instructional models in public health higher education. BMC Med. Educ. 2014, 14, 181. [CrossRef] [PubMed]

31. Bishop, L.; Verleger, M. The Flipped Classroom: A Survey of the Research. In Proceedings of the 2013 ASEE Annual Conference \& Exposition, Atlanta, GA, USA, 25 June 2013; p. 6219.

32. Krathwohl, D.; Anderson, L.W. A Revision of Bloom's Taxonomy: An Overview. Am. J. Psychol. 2009, 122, 39-52. [CrossRef]

33. Ericsson, K.A. Deliberate practice and the acquisition and maintenance of expert performance in medicine and related domains. Acad. Med. 2004, 79, S70-S81. [CrossRef] [PubMed]

34. Busari, J.O.; Scherpbier, A.J. Why residents should teach: A literature review. J. Postgrad. Med. 2004, 50, 205-210. [PubMed]

35. Berkenbosch, L.; Muijtjens, A.M.M.; Zimmermann, L.J.I.; Heyligers, I.C.; Scherpbier, A.J.J.A.; Busari, J.O. A pilot study of a practice management training module for medical residents. BMC Med. Educ. 2014, 14, 107. [CrossRef] [PubMed]

36. Fylan, F. Semi-structured interviewing. In A Handbook of Research Methods for Clinical and Health Psychology; Oxford University Press: New York, NY, USA, 2005; pp. 65-67.

37. Fick, U. An Introduction to Qualitative Research, 2nd ed.; Sage Publishing: London, UK, 2002; pp. $176-195$.

38. Kurup, V.; Hersey, D. The changing landscape of anesthesia education: Is Flipped Classroom the answer? Curr. Opin. Anaesthesiol. 2013, 26, 726-731. [CrossRef] [PubMed]

39. Butt, A. Student views on the use of lecture time and their experience with a flipped classroom approach. Bus. Educ. Accredit. 2014, 6, 33-43. [CrossRef]

40. Kerfoot, B.; Conlin, P.; Travison, T.; McMahon, G. Web-Based Education in Systems-Based Practice: A randomized trial. Arch. Intern. Med. 2007, 167, 361-366. [CrossRef] [PubMed]

41. Rowe, M.; Frantz, J.; Bozalek, V. Beyond knowledge and skills: The use of a Delphi study to develop a technology-mediated teaching strategy. BMC Med. Educ. 2013, 13, 51. [CrossRef] [PubMed] 